\title{
Current Management and Future Opportunities for Peritoneal Metastases
}

\author{
David L. Bartlett, MD \\ University of Pittsburgh, UPMC Health System, Pittsburgh, PA
}

Peritoneal metastases represent a site and stage of cancer that causes more severe suffering than any other, and it is an extremely common problem. In one large study, $8 \%$ of colon cancer patients presented with peritoneal metastases, and an additional $5 \%$ experienced peritoneal metastases after curative resection. ${ }^{1}$ Combined with the $30 \%$ of gastric cancer patients who have peritoneal metastases and the majority of ovarian cancer patients, the numbers become significant.

Peritoneal metastases deserve special attention for the distinctiveness of the diagnosis, prevention, treatment, and palliation. Although medical oncologists have not placed much emphasis on this unique site of disease, surgical oncologists have recognized the dreadful nature of this problem and have specifically addressed it.

The surgical management of peritoneal metastases has been initiated and promoted throughout the world by Paul Sugarbaker. His original description of peritonectomy, ${ }^{2}$ his early use of intraperitoneal chemotherapy, ${ }^{3}$ and his early adoption of heated intraperitoneal chemotherapy (HIPEC) ${ }^{4}$ established the field of peritoneal surgery, and hundreds of surgeons have followed in his footsteps. His confident, emphatic approach has sparked a wave of international focus and research that has cemented the field and affected the lives of thousands of patients. Nevertheless, as with many surgical innovations, the practice has evolved faster than the data to support it, leaving many skeptics and critics.

The most common surgical treatment applied to peritoneal metastases from gastrointestinal primaries is cytoreductive surgery (CRS) and HIPEC. The CRS

\section{(C) Society of Surgical Oncology 2018}

First Received: 3 May 2018;

Published Online: 8 June 2018

D. L. Bartlett, MD

e-mail: bartdl@upmc.edu; bartlettdl@upmc.edu procedure is an important technique that for advanced tumors requires skill, experience, aptitude, and fortitude. The peritoneal surgeon must navigate throughout an adhesion-filled abdominal cavity and be prepared to comfortably perform everything from a pelvic peritonectomy with en bloc hysterectomy and proctectomy to careful resection of cemented tumor under the suprahepatic vena cava to distal pancreatectomy, gastrectomy, duodenal resection, ureteral stripping, periportal dissection, caudate resection, and more, often all in a single case. It requires a team of physicians, nurses, and ancillary staff dedicated to safe outcomes and minimal discomfort including personnel from the outpatient clinic, the operating room, the intensive care unit, the hospital floors, rehabilitation units, pain services, and palliative care teams. With this universal support, it still is a challenging procedure. Patients undergo 12-h operations with a $3.5 \%$ chance of dying before recovery from the operation and needing 6 months to return to a good quality of life. ${ }^{5}$

The HIPEC treatment started with a description of the perfusion system in a canine model in $1980^{6}$ and a case report from the same authors at the University of Louisville. ${ }^{7}$ Next, a series of reports from Japan concerning gastric cancer were published, including randomized trials. ${ }^{8-10}$ In the early 1990s, the French groups began reporting outcomes, ${ }^{11}$ and articles from Sugarbaker's team ${ }^{12}$ and Loggie et al., ${ }^{13}$ as well as prospective clinical trials from Alexander and Fra$\operatorname{ker}^{14,15}$ emerged from the United States.

The first randomized trial for something other than gastric cancer was reported by Verwaal et al. ${ }^{16}$ from the Netherlands, who reported on colon cancer in 2003. This trial demonstrated a remarkable survival advantage for CRS and HIPEC, but the control arm of the study used systemic 5-fluorouracil (5-FU) alone, an ineffective agent.

By 2005, more than 200 articles on the use of HIPEC were published, with a paucity of level 1 data. This flood of reports pushed the field forward in the absence of definitive 
clinical trials. Also problematic, the techniques varied greatly from $30 \mathrm{~min}$ of mild hyperthermia and oxaliplatin to $2 \mathrm{~h}$ of mitomycin $\mathrm{C}$ and severe hyperthermia, with everything in between. Sound pharmacokinetic analysis, an understanding of drug sensitivity, and the in vitro requirements for hyperthermia often were ignored or unavailable. To date, more than 1500 articles have been published on HIPEC, and more than 500 institutions across the world are performing CRS and HIPEC as the standard of care for peritoneal metastases, with many of the same limitations.

This educational review aims to update the readers on the most current recommendations for the management of peritoneal metastases from colorectal cancer, ${ }^{17}$ mesothelioma, ${ }^{18}$ and mucinous appendiceal neoplasms; ${ }^{19}$ to describe the state of the art for cytoreductive surgery and HIPEC; ${ }^{20}$ and to inform the readers on the important options for palliative management of peritoneal metastases. $^{21}$ We have solicited articles from thoughtful, highvolume experts in the field of peritoneal surgery so the reader can be confident that the existing data and recommendations are interpreted with a measure of personal experience and common sense.

In addition to understanding the existing data, it is essential to appreciate that many ongoing randomized trials across the world will continue to enlighten us about the role for HIPEC in the management of peritoneal metastases. A recent randomized trial of HIPEC in ovarian cancer was published in the New England Journal of Medicine, demonstrating a remarkable 13-month advantage in median overall survival for those patients receiving a 90-min HIPEC with cisplatin after cytoreduction compared with cytoreduction alone. $^{22}$

Although these results are consistent with those reported for gastrointestinal tumors and support the role of HIPEC for peritoneal metastases in general, it is also important to appreciate that the management of peritoneal metastases goes beyond HIPEC. It is incumbent on peritoneal surgeons to develop better treatments focused on the peritoneal cavity. For example, peritoneal metastases are uniquely accessible to biologic agents, such as oncolytic viruses which are ineffective when delivered systemically. $^{23}$ Intraperitoneal delivery of chimeric antigen receptor (CAR) $\mathrm{T}$ cells may be superior to systemic delivery. $^{24}$

The specialty of peritoneal surgery is here to stay. Peritoneal surgery is an important subspecialty within general surgical oncology, and peritoneal surgeons are going to be the drivers for advancements in the management of peritoneal metastases. It is a subspecialty that does not overlap with others and exists beyond the scope and interest of most general surgeons. As with almost all cancers, a multidisciplinary approach is essential, and tumor boards focused on peritoneal metastases will lead to the best outcomes. These unfortunate patients, who suffer with distention, pain, vomiting, profound weakness, and malnutrition, deserve special attention.

DISCLOSURE There are no conflicts of interest.

\section{REFERENCES}

1. Jayne DG, Fook S, Loi C, Seow-Choen F. Peritoneal carcinomatosis from colorectal cancer. Br J Surg. 2002;89:1545-50.

2. Sugarbaker PH, Kern K, Lack E. Malignant pseudomyxoma peritonei of colonic origin: natural history and presentation of a curative approach to treatment. Dis Colon Rectum. 1987;30:772-9.

3. Sugarbaker PH, Gianola FJ, Speyer JC, Wesley R, Barofsky I, Meyers CE. Prospective, randomized trial of intravenous versus intraperitoneal 5-fluorouracil in patients with advanced primary colon or rectal cancer. Surgery. 1985;98:414-22.

4. Jacquet P, Averbach AM, Stephens AD, Sugarbaker PH. Cancer recurrence following laparoscopic colectomy: report of two patients treated with heated intraperitoneal chemotherapy. Dis Colon Rectum. 1995;38:1110-4.

5. Dodson RM, McQuellon RP, Mogal HD, et al. Quality-of-life evaluation after cytoreductive surgery with hyperthermic intraperitoneal chemotherapy. Ann Surg Oncol. 2016;23:772-83.

6. Spratt JS, Adcock RA, Sherrill W, Travathen S. Hyperthermic peritoneal perfusion system in canines. Cancer Res. 1980;40:253-5.

7. Spratt JS, Adcock RA, Muskovin M, Sherrill W, McKeown J. Clinical delivery system for intraperitoneal hyperthermic chemotherapy. Cancer Res. 1980;40:256-60.

8. Koga S, Hamazoe R, Maeta M, Shimizu N, Murakami A, Wakatsuki T. Prophylactic therapy for peritoneal recurrence of gastric cancer by continuous hyperthermic peritoneal perfusion with mitomycin C. Cancer. 1988;61:232-7.

9. Fujimura T, Yonemura Y, Muraoka K, et al. Continuous hyperthermic peritoneal perfusion for the prevention of peritoneal recurrence of gastric cancer: randomized controlled study. World J Surg. 1994;18:150-5.

10. Yonemura Y, Fujimura T, Fushida S, et al. Hyperthermochemotherapy combined with cytoreductive surgery for the treatment of gastric cancer with peritoneal dissemination. World $J$ Surg. 1991;15:530-5; discussion 5-6.

11. Gilly FN, Sayag AC, Carry PY, et al. Intraperitoneal hyperthermic chemotherapy in the treatment of peritoneal carcinosis of digestive origin: a case report and physiopathology. J Chir. 1990;127:95-8.

12. Stephens AD, Belliveau JF, Sugarbaker PH. Intraoperative hyperthermic lavage with cisplatin for peritoneal carcinomatosis and sarcomatosis. Cancer Treat Res. 1996;81:15-30.

13. Loggie BW, Perini M, Fleming RA, Russell GB, Geisinger K. Treatment and prevention of malignant ascites associated with disseminated intraperitoneal malignancies by aggressive combined-modality therapy. Am Surg. 1997;63:137-43.

14. Alexander HR, Fraker DL. Treatment of peritoneal carcinomatosis by continuous hyperthermic peritoneal perfusion with cisplatin. Cancer Treat Res. 1996;81:41-50.

15. Bartlett DL, Buell JF, Libutti SK, et al. A phase I trial of continuous hyperthermic peritoneal perfusion with tumor necrosis factor and cisplatin in the treatment of peritoneal carcinomatosis. Cancer. 1998;83:1251-61.

16. Verwaal VJ, van Ruth S, de Bree E, et al. Randomized trial of cytoreduction and hyperthermic intraperitoneal chemotherapy 
versus systemic chemotherapy and palliative surgery in patients with peritoneal carcinomatosis of colorectal cancer. J Clin Oncol. 2003;21:3737-43.

17. Jacobson R, Sherman SK, Dadaleh F, Turaga KK. Peritoneal metastases in colorectal cancer. Ann Surg Oncol. 2018. https://d oi.org/10.1245/s10434-018-6490-x.

18. Alexander HR Jr, Li CY, Kennedy TJ. Current management and future opportunities for peritoneal metastases: peritoneal mesothelioma. Ann Surg Oncol. 2018. https://doi.org/10.1245/s1 0434-018-6337-5.

19. Choudry HA, Pai RK. Management of mucinous appendiceal tumors. Ann Surg Oncol. 2018. https://doi.org/10.1245/s10434018-6488-4.

20. Dodson RM, Kuncewitch M, Votanopoulos KI, Shen P, Levine EA. Techniques for cytoreductive surgery with hyperthermic intraperitoneal chemotherapy. Ann Surg Oncol. 2018. https://doi. org/10.1245/s10434-018-6336-6.
21. Lambert LA, Wiseman J. Palliative management of peritoneal metastases. Ann Surg Oncol. 2018. https://doi.org/10.1245/s104 34-018-6335-7

22. van Driel WJ, Koole SN, Sikorska K, et al. Hyperthermic intraperitoneal chemotherapy in ovarian cancer. $N$ Engl J Med. 2018;378:230-40.

23. Liu Z, Ravindranathan R, Kalinski P, Guo ZS, Bartlett DL. Rational combination of oncolytic vaccinia virus and PD-L1 blockade works synergistically to enhance therapeutic efficacy. Nat Comm. 2017;8:14754.

24. Katz SC, Point GR, Cunetta M, et al. Regional CAR-T cell infusions for peritoneal carcinomatosis are superior to systemic delivery. Cancer Gene Ther. 2016;23:142-8. 